\title{
A RANDOM COEFFICIENT VAR TRANSITION MODEL OF THE CHANGES IN LAND USE IN THE BRAZILIAN AMAZON
}

Lykke E. Andersen ${ }^{1}$

Clive W.J. Granger ${ }^{2}$

Eustáquio J. Reis ${ }^{3}$

\section{Resumo}

O artigo utiliza vetores auto-regressivos (VAR) para estimar modelos de transição com base em dados de painëis, tendo em conta que os parâmetros de transição para as diferentes regiōes podem não ser idênticos. O método é aplicado a um modelo da dinâmica do uso de terras na Amazônia brasileira, com a pretensão de subsidiar o entendimento do processo de desflorestamento da maior floresta ombrófla remanescente do planeta.

\section{Abstract}

This paper shows how a VAR transition model can be estimated from panel data, taking into account that the transition coefficients may not be identical across regions. The method is applied to a model of dynamic land use changes in Brazil's Amazon region. The model is intended to shed light on the deforestation process in the world's largest remaining rain forest.

Palavras-Chave: Short panels, random coefficients, transition models, Monte Carlo simulation, deforestation

Código JEL: C13, C33, Q15, Q23

1 Centre for Non-linear Economic Modelling, Dept. of Economics, Univ. of Aarhus, Danmark. This work was done whilethe first author was visiting theDept. of Economics, Univ. of California, San Diego, and the hospitality of the department is gratefully acknowledged.

2 Department of Economics, University of California, San Diego, USA. The research is supported by NSF Grant SBR-930081 and is part of a larger project investigating the dynamics and economics of deforestation.

${ }^{3}$ Institute for Applied Economic Research, Rio de Janeiro.

\begin{tabular}{llllllll}
\hline R. de Econometria & Rio de Janeiro & v. 17, & $\mathrm{n}^{0}$ & 1, & pp. 1-13 & Maio 1997 \\
\hline
\end{tabular}




\section{Introduction.}

When working with panel data it is important to recognize that while parameters may remain constant over time, they are less likely to be identical across individuals. This is particularly true when the individuals are very heterogeneous, as are for example countries, states, or municipalities in a cross section.

This paper is concerned with a particular type of models that arises when modelling dynamic transitions of a variable number of units between a fixed number of states/categories. It is essentially a Vector Autoregression allowing for random coefficients. In the application, the transition model is used to model the dynamic changes of land uses in the Brazilian Amazon, but the method could be used in a variety of situations where it is of interest to know the flows between states, while it is impossible to track each unit individually. In our case it is obviously impossible to track each plot of land in the more than 500 million hectares comprising the Brazilian Amazon. Thus, we have to work with aggregated data. The data set ${ }^{1}$ covers $N=316$ consistently defined municipalities at $T=3$ points in time $(1975,1980,1985)$. For each municipality, in each period, we observe the share of total land falling into each of $k$ categories of land use. In this application, the data is grouped into $p=3$ main categories; crops land ${ }^{2}$, pasture ${ }^{3}$ and fallow land ${ }^{4}$. Land not falling into one of these categories is considered virgin/uncleared land.

From the data it is possible to calculate the changes in each share, as well as the increase in total cultivated land (which is equal to the decrease in virgin land). But in order better to understand

1 The data is extracted from a very comprehensive data base on Legal Arrazonia. The data base is constructed and maintained at IPEA/DIPES in Rio de Janeiro and the data set is in the process of being expanded both backwards and forwards in time.

2 Crops land covers annual crops, perennial crops and planted forest.

3 Pasture is planted pasture only. Natural pasture is considered virgin/uncultivated.

4 Fallow land includes short fallow, long fallow, and non-usable land (roads, dams, etc.) 
the dynamics of deforestation it is also of interest to know the flows between each category. These flows cannot be calculated directly from the data, but they can be estimated if we are willing to make some assumptions.

The sequence of land use changes is expected to go in the direction: virgin land $\rightarrow$ crop land $\rightarrow$ pasture $\rightarrow$ fallow land, because the removal of the protective forest cover will lead to a rapid degradation

of the fragile soil of the rain forest. This uni-directional constraint, however, is not supported by the data, so our model is set up without such constraints.

In the following section, we set up the formal model and discuss the assumptions. Section 3 shows how the model can be estimated. Section 4 concludes.

\section{The Model.}

Let $Y_{j t}$ be a $p \times 1$ vector containing the $p$ land use shares for municipality $j$ at time $t$. Let $\Delta x_{j t}$ be newly cleared land (i.e., the share of total land that is converted from virgin land to cultivated land in the period between time $t-1$ and time $t$ ).

The basic model describing the land use dynamics in region $j$ can then be represented as a Vector Autoregression with $p$ equations:

$$
Y_{j t}=\alpha_{j} \Delta x_{j t}+A_{j} Y_{j, t-1}
$$

where $\alpha_{j}$ is a $p \times 1$ vector and $A_{j}$ is a $p \times p$ matrix. The coefficients of the model can be interpreted as transition coefficients. Thus, $\alpha_{1}$ is the share of newly cleared land that turns into category 1 cultivated land, and $A_{12}$ is the share of category 2 land that turns into category 1 land between period $t-1$ and period $t$. To account for all land the coefficients should sum to one vertically. Thus, we have the following constraint on the coefficients:

$$
\begin{aligned}
& i^{\prime} \alpha_{j}=1 \\
& i^{\prime} A_{j}=i^{\prime}
\end{aligned}
$$

Revista de Econometria 17 (1) Maio 1997 
where $i$ is a $p \times 1$ vector of ones.

For every region and every time period there is an identity in the data

$$
\Delta x_{j t} \equiv i^{\prime} Y_{j t}-i^{\prime} Y_{j, t-1}
$$

which arises because of the assumption that no land can disappear. Thus, newly cleared land equals the difference between total cultivated land at time $t$ and total cultivated land at time $t-1$.

If we insert the data identity (3) into our model (1) and rearrange, we get:

$$
\left(I-\alpha_{j} \dot{\imath}^{\prime}\right) Y_{j t}=\left(A_{j}-\alpha_{j} i^{\prime}\right) Y_{j, t-1}
$$

Solving for $Y_{j t}$ requires inverting the $p \times p$ matrix $\left(I-\alpha_{j} i^{\prime}\right)$, which is impossible because the coefficient constraints implies that this matrix does not have full rank. Thus, there seems to be a singularity problem.

The trick is to notice that the data constraint (3) implies that the coefficient constraints (2) hold identically. One of the equations in the model can therefore be eliminated without any loss of information. Let $\tilde{Y}_{j t}$ be any $p-1$ rows of $Y_{j t}$, and let $\tilde{\alpha}_{j}$ and $\tilde{A}_{j}$ be the corresponding $p-1$ rows of $\alpha_{j}$ and $A_{j}$, respectively. Now there are no constraints on $\widetilde{\alpha}_{j}$ and $\widetilde{A}_{j}$, and $\Delta x_{t j}$ cannot be calculated from $\tilde{Y}_{j t}$ and $\tilde{Y}_{j, t-1}$. Thus, it is possible to estimate the coefficients in the following $p-1$ equation system:

$$
\tilde{Y}_{j t}=\tilde{\alpha}_{j} \Delta x_{t j}+\tilde{A}_{j} \tilde{Y}_{j, t-1}
$$

The coefficients for the last equation can then be calculated residually from the coefficient constraints. A proof of the fact that the coefficients sum to one is given in the Appendix.

Since there is no need to impose any constraints on the system (they impose themselves through the data constraints), we can estimate each equation (including the last one) individually by OLS. 
This is easier than using a system estimation method and the coefficient estimates will be the same.

\section{The fixed coefficient model}

If all coefficients are the same across regions, the data can be pooled and system (1) can be estimated by OLS. This will give unbiased estimates, $\widehat{\alpha}$ and $\hat{A}$ of the common transition coefficients, $\alpha$ and $A$.

However, if $\alpha$ and $A$ are not identical across municipalities, then $\widehat{\alpha}$ and $\widehat{A}$ will be biased.

\section{The random coefficient model}

Assume that the coefficients $\alpha_{j}$ and $A_{j}$ are independently and normally distributed across regions with means $\bar{\alpha}_{(p \times 1)}$ and $\bar{A}_{(p \times p)}$ and variances $\sigma_{\alpha(p \times 1)}$ and $\sigma_{A(p \times p)}$. The coefficient constraints (2) must still hold for each municipality, so the coefficients are not independent across equations.

Since we only have observations at 3 points in time, there are insufficient degrees of freedom to estimate separate coefficients for each municipality. The most we can hope for, is to be able to estimate the mean and the variance of the distribution of each coefficient. It would be convenient if the OLS estimates from the fixed coefficient case would provide unbiased estimates of the mean of the random coefficients, but unfortunately this is not so. This can be seen from the following random coefficient model:

$$
Y_{j t}=\bar{\alpha} \cdot \Delta x_{j t}+\bar{A} \cdot Y_{j, t-1}+\varepsilon_{j t}
$$

where

$$
\varepsilon_{j t}=\left(\alpha_{j}-\bar{\alpha}\right) \Delta x_{j t}+\left(A_{j}-\bar{A}\right) Y_{j, t-1} .
$$

Any systematic correlation between the true coefficients and the land use structure would lead to biased OLS estimates. If, for example, some municipalities have soils that are particularly suited for 
growing crops, then we would expect the crop-share to be relatively high and the crop-to-crop transition coefficient to be above average. Such a positive correlation would imply an upward biased estimate of the average crop-to-crop coefficient. The bias would be reinforced by municipalities with poor soil and therefore low crop shares and lower than average crop-to-crop coefficients.

It follows from (6) that an estimate of the variance of the coefficients can be obtained by regressing the squared residuals on the squared regressors. If the variances are close to zero the OLS estimates $\widehat{\alpha}$ and $\widehat{A}$ will be unbiased estimates of $\bar{\alpha}$ and $\bar{A}$. But as the variance of the coefficients increase the OLS estimates will become increasingly biased, because of the correlation between the error terms and the regressors.

\section{Estimating the Model.}

This section shows how to get unbiased estimates of the mean of each coefficient in the transition model. It is a four-step process. First, the model is estimated by OLS as if the coefficients were fixed. Then the variance of each coefficient is estimated by regressing the squared residuals from each equation on a constant and the squared regressors. The estimated variances are then used in a series of Monte Carlo simulations to obtain the biases. Finally, the original OLS estimates are corrected by subtracting the estimated biases.

\section{Estimating the fixed coefficient model by OLS}

All cleared land $\left(C L R_{t}\right)$ in each municipality fall into one of the following three categories; crops land $\left(C R P_{t}\right)$, pasture $\left(P A S_{t}\right)$, or fallow land $\left(F A L_{t}\right)$.

Pooling all observations and estimating the fixed coefficient transition model by OLS yields the following results: 
Lykke E. Andersen; Clive W.J. Granger \& Eustáquio J. Reis

$$
\begin{aligned}
& C R P_{t}=0.1061 \cdot \Delta C L R_{t}+0.6647 \cdot C R P_{t-1}+0.0105 \cdot P A S_{t-1}+ \\
& \text { (0.0061) (0.0285) (0.0077) } \\
& +0.0771 \cdot F A L_{t-1} \\
& \text { (0.0072) } \\
& P A S_{t}=0.2919 \cdot \triangle C L R_{t}-0.0439 \cdot C R P_{t-1}+\text { 1.1543. } P A S_{t-1}+ \\
& \text { (0.0121) (0.0570) (0.0154) } \\
& +0.1114 \cdot F A I_{t-1} \\
& (0.0144) \\
& F A L_{t}=0.6020 \cdot \Delta C L R_{t}+0.3792 \cdot C R P_{t-1}-0.1648 \cdot P A S_{t-1}+ \\
& \text { (0.0126) (0.0592) (0.0160) } \\
& +0.8115 \cdot F A L_{t-1} \\
& \text { (0.0150) }
\end{aligned}
$$

The $R^{2}$ s are $0.8222,0.9480$, and 0.9344 , respectively. The numbers in parentheses are the estimated standard errors. Notice that the coefficients sum exactly to one vertically, even though we have not imposed any constraints during estimation. This fact does not imply anything about the validity of the model; the summation result would hold even if the true coefficients vary from region to region or if the model is mis-specified in other ways.

\section{Estimating the variance of the coefficients}

It is possible to obtain a crude estimate of the true variance of each coefficient by regressing the squared residuals from each equation on the squared regressors and a constant. The coefficient of each squared regressors will then be the estimate of the variance of the corresponding coefficient. Applying this method, we find that the variances on the three $C R P_{t-1}$ coefficients are approximately 0.09 , while the variances of the other coefficients are indistinguishable from 
zero. I.e.

$$
\hat{\sigma}_{\alpha}=\left[\begin{array}{l}
0 \\
0 \\
0
\end{array}\right] \text { and } \hat{\sigma}_{A}=\left[\begin{array}{lll}
0.09 & 0 & 0 \\
0.09 & 0 & 0 \\
0.09 & 0 & 0
\end{array}\right]
$$

\section{Estimating the bias of the coefficients}

Assuming that the true coefficients are normally distributed with means according to the OLS estimates in (7) and variances according to (8), we can generate artificial data series following $(1)^{5}$. If a large number of models are estimated with artificially generated data we can compare the average estimated coefficients with the known true coefficients.

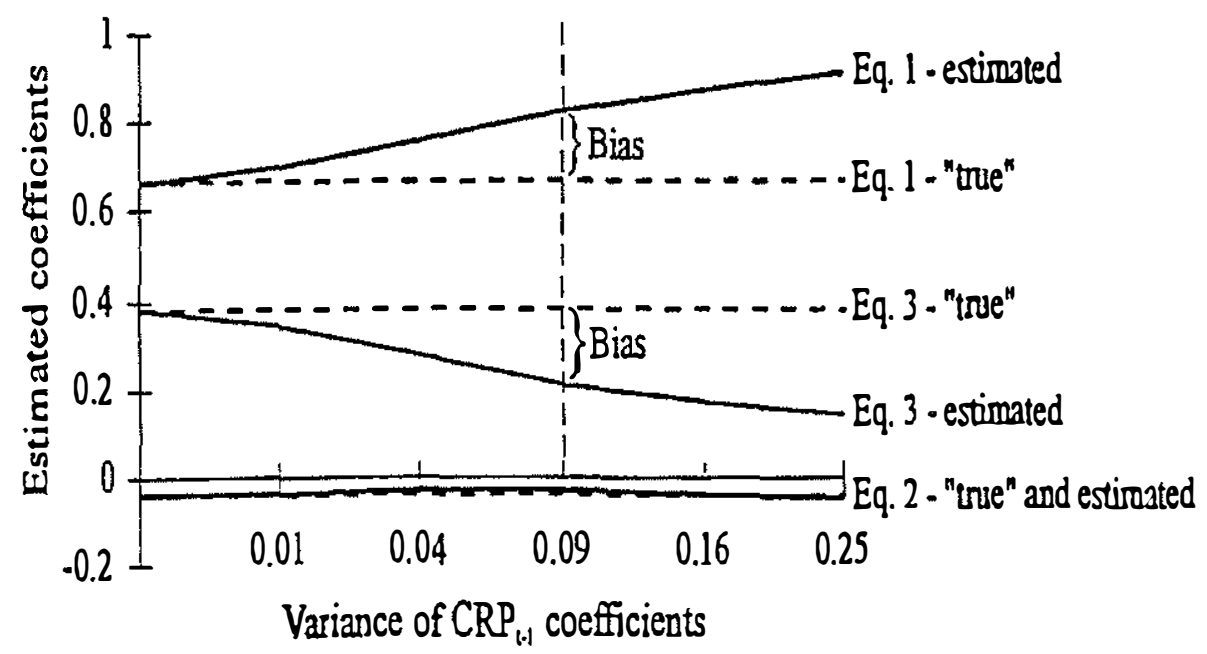

Figure 1: Bias estimates from first iteration.

5 To make the artificial data sets look as ruch like the real as possible, we chose the true land use shares for each runicipality as initial values, and the true changes in cleared land for each municipality as $\triangle C L R_{t}$ in each period. The variance of the error terms was chosen to make the $R^{2}$ s for the artificial model the sarne size as in the original OLS model. 
It turns out that all coefficients, not only those with positive variance, are biased. And the biases are big compared to the standard errors of the estimated coefficients. The biases increase with the variance of the coefficients, but they always sum to zero for each column. Figure 1 shows the biases of the three $C R P_{t-1}$ coefficients after first iteration.

Consider, for example, the $C R P$ coefficient from Eq. 1 . If the mean of this coefficient were truly 0.66 and the variance across municipalities 0.09 , then the simple OLS estimate would be approximately 0.80 , i.e. strongly upward biased. Since our OLS estimate was 0.66 we have to adjust our expectations on the true value downwards until the simulated estimate coincides with the OLS estimate. Because of the constraints in the data, the coefficients and the biases are not independent across equations. Therefore the whole system has to be estimated simultaneously and repeatedly until all simulated coefficient estimates have converged to the simple OLS estimates.

Notice that the biases approach zero as the variance of the coefficients goes to zero, confirming that the procedure yields unbiased estimates in the fixed coefficient case.

Applying this method, we find that the biases in our OLS model are approximately:

$$
\widehat{b i a s}^{*}=\left[\begin{array}{cccc}
-0.01 & 0.16 & -0.01 & -0.03 \\
0.00 & 0.01 & 0.02 & -0.01 \\
0.01 & -0.17 & -0.01 & 0.04
\end{array}\right]
$$

which means that our best estimate of the coefficients become:

$$
\left[\widehat{\alpha}^{*}, \widehat{A}^{*}\right]=\left[\begin{array}{cccc}
0.12 & 0.50 & 0.01 & 0.11 \\
0.29 & -0.05 & 1.13 & 0.12 \\
0.59 & 0.55 & -0.14 & 0.77
\end{array}\right]
$$




\section{Conclusion.}

When estimating models based on cross-region or cross-country panel data sets it is important to take into account that coefficients may not be identical across regions. The present paper has shown how this can be done even for panels with a very short time-series dimension.

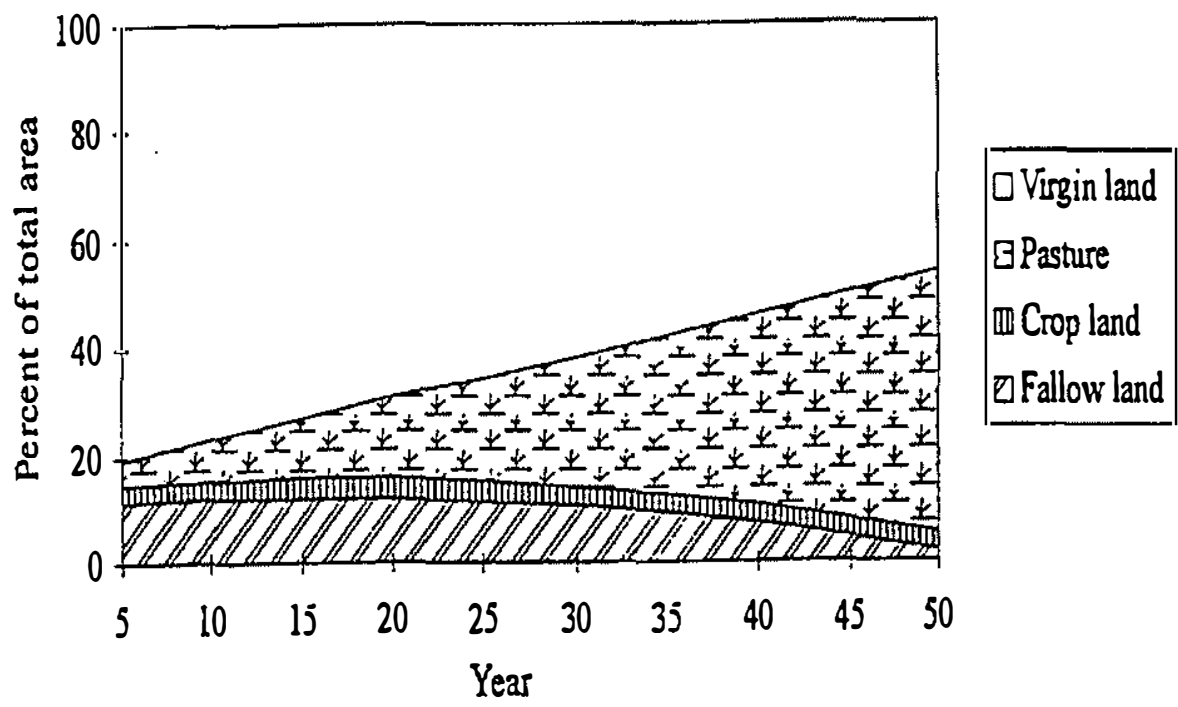

Figure 2: Projected changes in land use for average municipality

The results indicate that pasture, rather than fallow land, is the "absorbing" land use category. A projection of the changes in land uses for an average municipality is shown in Figure 2. The projection is based on the average speed of clearing for the period 1975-85, which was $3.82 \%$ of total land per five year period. At that speed there will be almost no virgin rain forest left in the Amazon region in 100 years. It should be stressed that this model does not try to explain the underlying causes of deforestation, and can therefore 
not be used to predict future rates of deforestation ${ }^{6}$. This model rather analyses past land use dynamics to predict what deforested land is going to look like in the future unless these land use practices are changed.

Compared to the simple (biased) OLS estimates this model predicts a slightly less aggressive expansion of pasture ${ }^{7}$. The results are still alarming, though, because pastures have been shown to be one of the least sustainable and least desirable alternatives to a standing rain forest. Cattle ranching requires lots of space, generates little employment, and has a very low (if not negative) productivity (e.g. Goodland 1980, Hecht et al 1988, Mahar 1989, and Andersen et al 1996). Crop land, on the other hand, may potentially generate sufficient income and employment opportunities to justify at least some forest conversion (Andersen et al 1996).

Our analysis confirms what the settlers discovered after only a few years in the Amazon: Most of the soil in the region is unsuitable for sustainable agriculture. Most crop land (50-60\%) is deserted within a five-year period because of dwindling yields. Without additional income from wage labor (for example from land clearing for the big ranches), the settlers could not make ends meet and were forced to try their luck further into the rain forest thereby causing additional deforestation. Part of the fallow land left over after the peasants would then be appropriated by the ranches who needed ever expanding pastures to feed even a constant cattle population.

6 Econornetric models of the underlying causes of deforestation in the Brazilian Arrazon are developed in Reis and Guzmán (1994), Andersen (1996, 1997), Andersen et al (1996), and Pfaff (1996).

7 The dramatic expansion of pasture may still be overstated. The design of the privatization policies in the Amazon region have led people to clain idle lands as pastures in order to receive subsidies and be granted property rights (May \& Reis, 1992). Thus, some land categorized as pasture may never actually have seen a cow. 


\section{Appendix.}

Proof that the transition coefficients sum to one vertically. Consider the easy case where we only have data from two time periods, and write the $k^{\text {th }}$ equation of the transition model (1) as:

$$
y_{j t}^{(k)}=\alpha_{k} \cdot \Delta x_{j t}+\sum_{i=1}^{p} A_{k i} \cdot y_{j, t-1}^{(i)}+u_{j t}^{(k)}
$$

where $u_{j t}^{(k)}$ is an error term due to mis-specification. For simplification, drop the time subscripts and call the $(p+1) \times 1$ vector of explanatory variables $x_{j}$. Now stack the data values, so that $\underline{y}^{(k)}=\left(y_{1}^{(k)}, y_{2}^{(k)}, \ldots, y_{N}^{(k)}\right)^{\prime}, \underline{x}=\left(x_{i j}, i=1, \ldots, N, j=1, \ldots, p+1\right)$ and $\underline{u}^{(k)}=\left(u_{1}^{(k)}, u_{2}^{(k)}, \ldots, u_{N}^{(k)}\right)^{\prime}$. Then (9) becomes:

$$
\underline{y}^{(k)}=\underline{x}^{(k)}+\underline{u}^{(k)} \text {. }
$$

Standard results gives

$$
\widehat{\beta}^{(k)}=\left(\underline{x}^{\prime} \underline{x}\right)^{-1} \underline{x}^{\prime} \underline{y}^{(k)} .
$$

Now define $\underline{\widehat{\beta}}=\left(\widehat{\beta}^{(1)}, \widehat{\beta}^{(2)}, \ldots, \widehat{\beta}^{(p)}\right)=\left(\underline{x}^{\prime} \underline{x}\right)^{-1} \underline{x^{\prime}} \underline{y}$, where $\underline{y}=$ $\left(\underline{y}^{(1)}, \underline{y}^{(2)}, \ldots, \underline{y}^{(p)}\right)$. Then

$$
\underline{\hat{\beta}} \underline{i}=\left(\underline{x}^{\prime} \underline{x}\right)^{-1} \underline{x}^{\prime} \underline{y} \underline{\underline{y}} .
$$

With our new notation, the data constraint (3) can be written as $\underline{y} \underline{i}=\underline{x i}$, so

$$
\underline{\hat{\beta}} \underline{i}=\underline{i}
$$

i.e. the coefficients sum to one across $k$.

To generalize to the panel situation, we just have to stack the data appropriately, so that each time period is treated as a new region. This just means that the $N$ dimension expands to $N \cdot T$. Otherwise, the results will be the same.

Submetido em Setembro de 1996. Revisado em Abril de 1997. 
Lykke E. Andersen; Clive W.J. Granger \& Eustáquio J. Reis

\section{Referências}

Andersen, Lykke E. 1996. "The causes of deforestation in the brazilian Amazon." J. of Environment \& Development 5, 309-328.

Andersen, Lykke E. 1997. "Modelling the relationship between government policy, economic growth, and deforestation in the brazilian Amazon." Working Paper 1997-2, Department of Economics, University of Aarhus, Denmark.

Andersen, Lykke E.; Clive W. J. Granger; Eustáquio J. Reis; LingLing Huang \& Diana Weinhold. 1996. "Report on Amazon deforestation", Discussion Paper 96-40, Department of Economics, University of California, San Diego.

Brown, Katarina \& David W. Pearce. 1994. "The Causes of Tropical Deforestation." London: UCL Press.

Goodland, Robert J. A. 1980. "Environmental ranking of Amazonian development projects in Brazil." Environmental Conservation 7 (1), 9-26.

Hecht, Susanna B., R. B. Norgaard \& G. Possio. 1988. "The economics of cattle ranching in eastern Amazonia." Interciencia, (Caracas) 13 (5), 233-240.

Mahar, Dennis J. 1989. "Government Policies and Deforestation in Brazil's Amazon Region." A World Bank Publication.

May, Peter \& Eustáquio J. Reis. 1992. "The user structure of Brazil's Tropical Rainforest." Report prepared for Kiel Institute of World Economics.

Pfaff, Alexander S. P. 1996. "What drives deforestation in the brazilian Amazon? Evidence from satellite and socioeconomic data". MIT Joint Program on the Science and Policy of Global Change, Report No. 16, MIT.

Reis, Eustáquio. J. \& R.M. Guzmán. 1994. "An Econometric Model of A mazon Deforestation." In: Brown, K. and D.W.Pearce eds.: The Causes of Tropical Deforestation. London: UCL Press. 
